\title{
BM] Global Health Cost and cost-effectiveness of a parenting programme to prevent violence against adolescents in South Africa
}

\author{
Alice Redfern, ${ }^{1,2}$ Lucie D Cluver, ${ }^{1,3}$ Marisa Casale, ${ }^{1,4}$ Janina I Steinert ${ }^{1,5}$
}

To cite: Redfern A, Cluver LD, Casale $\mathrm{M}$, et al. Cost and costeffectiveness of a parenting programme to prevent violence against adolescents in South Africa. BMJ Glob Health 2019;4:e001147. doi:10.1136/ bmjgh-2018-001147

Handling editor Seye Abimbola

- Additional material is published online only. To view please visit the journal online (http://dx.doi.org/10.1136/ bmjgh-2018-001147).

Received 31 August 2018 Revised 6 March 2019 Accepted 9 March 2019
Check for updates

(C) Author(s) (or their employer(s)) 2019. Re-use permitted under CC BY-NC. No commercial re-use. See rights and permissions. Published by BMJ.

${ }^{1}$ Social Policy and Intervention, University of Oxford, Oxford, UK ${ }^{2}$ IDinsight, Nairobi, Kenya

${ }^{3}$ Psychiatry and Mental Health, University of Cape Town, Cape Town, South Africa

${ }^{4}$ School of Public Health, University of Western Cape, Cape Town, South Africa ${ }^{5}$ Department of Economics, Georg-August-Universitat Gottingen, Gottingen, Germany

Correspondence to Dr Alice Redfern; alice.redfern28@gmail.com

\section{ABSTRACT}

Introduction This paper presents the costs and costeffectiveness of 'Parenting for Lifelong Health: Sinovuyo Teen', a non-commercialised parenting programme aimed at preventing violence against adolescents in low-income and middle-income countries.

Methods The effectiveness of Sinovuyo Teen was evaluated with a cluster randomised controlled trial in 40 villages and peri-urban townships in the Eastern Cape of South Africa from 2015 to 2016. The costs of implementation were calculated retrospectively and models of costs at scale estimated, from the perspective of the programme provider. Cost-effectiveness analysis considers both the cost per incident of abuse averted, and cost per disability-adjusted life year averted. Potential economic benefits from the societal perspective were estimated by developing a framework of possible savings. Results The total implementation cost for Sinovuyo Teen over the duration of the trial was US $\$ 135954$, or US $\$ 504$ per family enrolled. Among the 270 families in the treatment group, an estimated 73 incidents of physical and emotional abuse were averted $(95 \% \mathrm{Cl} 29$ to 118 incidents averted). During the trial, the total cost per incident of physical or emotional abuse averted was US\$1837, which is likely to decrease to approximately US $\$ 972$ if implemented at scale. By comparison, the economic benefits of averting abuse in South Africa are large with an estimated lifetime saving of US\$2724 minimum per case. Conclusion Parenting programmes are a cost-effective intervention to prevent the abuse of adolescents by their caregivers in South Africa, when compared with existing violence prevention programmes and cost-effectiveness thresholds based on GDP per capita.

\section{BACKGROUND}

A recent systematic review using data from 96 countries found that approximately 1 billion children globally experience some form of violence each year. ${ }^{1}$ Exposure to violence during childhood and adolescence is associated with serious long-term consequences. Abused individuals are at significantly higher risk of developing long-term depressive disorders, anxiety and suicidal behaviour, ${ }^{2}{ }^{3}$ as

\section{Key questions}

What is already known?

- There is limited literature on effective interventions to prevent violence against adolescents in low-income and middle-income countries, where the burden of maltreatment is highest.

- An increasing body of evidence suggests that parenting programmes effectively reduce parental abuse, but very little is known about their cost or cost-effectiveness in low-resource settings.

What are the new findings?

- A non-commercialised programme offered by Parenting for Lifelong Health can be implemented at a cost per family that is substantially lower than comparable programmes in high-income countries, while maintaining effectiveness across a broad range of outcomes.

- Based on the cost per incident of abuse prevented, and estimated cost per disability-adjusted life year averted, the programme is cost-effective in comparison with existing violence prevention programmes in South Africa and thresholds based on GDP per capita.

- Given the high economic burden of abuse, the intervention is likely to be cost-saving, especially if run at scale.

What do the new findings imply?

- Parenting programmes are a cost-effective intervention for the prevention of abuse in low-resource settings, but more research in different contexts is critical.

well as childhood behavioural problems and subsequent conduct disorders. ${ }^{4}$ Physical abuse increases the risk of future alcoholism and substance abuse, particularly in men. ${ }^{4}$ All forms of abuse, not just sexual, are associated with an increased risk of contracting sexually transmitted infections (including HIV) and with risky sexual behaviour, ${ }^{4}$ along with other long-term physical health outcomes. ${ }^{34}$ Additionally, there is evidence of intergenerational 
continuity; the victims of abuse are at increased risk of becoming perpetrators in later life, continuing the cycle of violence through the generations. ${ }^{56}$

As a result of these long-term health and social impacts, the economic impact of violence against children and adolescents globally is substantial. While accurate prevalence data are missing for many countries, the cost of abuse worldwide has been estimated to fall within the range of US $\$ 1953$ billion to US $\$ 7116$ billion (or between $2 \%$ and $8 \%$ of global GDP). ${ }^{7}$

The burden of child and adolescent maltreatment is heaviest in low-income and middle-income countries (LMICs) where the prevalence of violence against children is higher ${ }^{8}$ and $95 \%$ of deaths due to childhood injuries occur. ${ }^{10}$ In South Africa, a recent nationally representative study found that $34.8 \%$ of adolescents aged 15 to 17 had experienced physical abuse in their life, $16.1 \%$ had experienced emotional abuse, $12.2 \%$ neglect, and $19.8 \%$ sexual abuse. ${ }^{11}$ A study by Save the Children of the economic value of violence against children in South Africa estimates the cost of abuse in 2015 alone was ZAR 202 billion, the equivalent to $5.1 \%$ of its GDP. ${ }^{12}$ This is in comparison with similar studies in the USA, ${ }^{13}$ Germany ${ }^{14}$ and Australia, ${ }^{15}$ which estimate the costs as $1 \%, 0.45 \%-$ $1.2 \%$ and $1.2 \%$ of GDP, respectively.

Given the high prevalence, wide-ranging negative impacts and economic burden of violence against children, there is a strong case for investing in affordable and effective preventative programmes. For over a decade, WHO has had a dedicated call for action to gather better evidence on how to successfully prevent child maltreatment. ${ }^{16}$ In high-income countries (HICs), an increasing body of literature demonstrates that parenting programmes can effectively prevent child maltreatment. A recent meta-analysis of the topic found an $11 \%$ reduction in abusive behaviour among caregivers receiving programmes in the USA and Canada. ${ }^{17}$ However, there is a clear evidence gap in LMICs.

Two recent systematic reviews looking specifically for evidence from parenting programmes in LMICs noted that while the body of evidence is growing, the vast majority of studies focus on very young children and do not look specifically at child maltreatment. ${ }^{18} 19$ Subsequent to these reviews, since 2013, the results of three randomised controlled trials (RCTs) of parenting interventions in Thailand ${ }^{20}$ (in adolescents), Liberia ${ }^{21}$ and Panama $^{22}$ (both in younger children) have been published. Overall, they found significant improvements in parent-child interactions and child behaviour, and reductions in harsh parenting among families receiving the interventions. This supports the notion that parenting programmes can be appropriately culturally adapted and can be effective in low-resource settings. However, this is still a field without sufficient high-quality research across different contexts and age groups.

In HICs, a number of studies on the cost-effectiveness of parenting programmes have been published ${ }^{23}{ }^{24}$ Even with high costs of delivery, several modelling studies have demonstrated that over the long term, such programmes become cost-saving from a societal perspective, mostly due to the high savings that can be made by reductions in risk of future health problems and delinquency. ${ }^{25-27}$ However, the costs of running such programmes in the UK, USA and Australia is higher than the per-capita budgetary health allocation in many LMICs. ${ }^{8}$ The importance of detailed costing and modelling of the cost-effectiveness of parenting programmes in LMICs has been highlighted as an area of priority for future research. ${ }^{8}$ To date, only one working paper on the economics of parenting training in LMICS has been published, giving the cost of running two small-scale pilots of parenting programmes, in Liberia and Thailand. ${ }^{28}$ They have demonstrated that it is possible to run such programmes at a considerably lower cost (US\$650-900 per beneficiary) while maintaining their effect. More studies on this topic are clearly required.

This paper presents a retrospective costing and cost-effectiveness analysis of a parenting programme for the prevention of abuse among adolescents in South Africa, using data from a pragmatic cluster RCT of the intervention. The parenting intervention resulted in statistically significant reductions in physical and emotional abuse, along with significant improvement across a number of secondary outcomes. Full results of the Sinovuyo parenting programme (including effects on secondary outcomes) are presented in Cluver et $_{\text {al. }}{ }^{29}$

\section{METHODS \\ Programme implementation}

'Sinovuyo Teen' is a group-based parenting programme attended by adolescents (aged 10-18) and their caregivers, developed as part of the WHO/Unicef 'Parenting for Lifelong Health' initiative, aimed at developing an evidencebased, non-commercialised programme to improve parenting practices and prevent child maltreatment risk in low-resource settings. The programme consists of 14 weekly sessions that are run by non-professional, local, trained facilitators. The programme was developed using the best evidence in parenting practices in HICs and adapted for the South African context. The manual is offered for free with the aim that it can be implemented, at scale, at low cost (the programme manuals are freely available at WHO website: http:/ / www.who.int/violence_ injury_prevention/violence/child/PLH-manuals/en/). The programme was implemented independently of the research team by a local NGO, Clowns Without Borders South Africa.

\section{Trial implementation}

Two pilots in $2013(\mathrm{n}=60)^{30}$ and $2014(\mathrm{n}=230)^{31}$ demonstrated positive results leading to a cluster RCT of the programme from January 2015 to April 2016. A total of 551 caregiver-teen dyads (1102 individuals) were recruited across 40 villages and townships in a rural/ peri-urban municipality in the Eastern Cape. High-risk 
families were identified through schools, social workers and chieftains (local traditional leaders) as well as through community recommendation, and approached for their informed consent. Randomisation of clusters into 20 treatment and 20 control groups was carried out by a blinded statistician. The control group received a brief handwashing programme focused on hygiene and safe water conservation, delivered in 1-day drama-based workshops by the same facilitators. Data collection involved baseline questionnaires for both the caregiver and teen before the programme implementation, a short questionnaire immediately following implementation and full follow-up questionnaires 5-9 months after implementation. Questionnaires were translated into the local language (Xhosa), back translated to ensure accuracy and answered on mobile tablets by participants, supported by local, trained research assistants. The full trial protocol has been published elsewhere. ${ }^{32}$

\section{Programme costs}

The costs of implementation of 'Sinovuyo Teen' during the trial were calculated retrospectively from the perspective of the provider, NGO Clowns Without Borders, using accounting records and monitoring data. The costs are divided into three principal categories: (1) Set-up costs, which includes costs required to prepare for implementation (ie, for community liaision and participant recruitment) and facilitator training. The manual had been fully developed prior to the trial, so no programme development costs were incurred; (2) Programme delivery costs, which corresponds to staff-time, transport costs, and all other materials required for workshop implementation. Included in these costs is staff-time dedicated to the ongoing mentoring of facilitators (in the form of a full day of supervision and training each week throughout implementation), and basic monitoring costs incurred by the implementing partner (eg, attendance lists, facilitator checklists); (3) Overheads, which includes the attributable proportion of office running costs and management support incurred by the NGO over the implementation period. All costs related to the evaluation of the programme that were incurred by the research team are excluded from this analysis.

There are a number of ways in which delivery of the programme during the trial is expected to deviate from delivery at scale. In order to account for the impact of these changes on the cost of the programme, we model the cost of implementation if it were to be delivered at scale in the same context. We modelled costs based on the assumption that the programme would be implemented by the same or a similar NGO, with a similar staffing structure, but delivered to 1000 families in 60 groups (compared with the 20 groups and 270 families included in the trial) in three 14-week waves over the course of 1 year. This differs substantially from implementation during the trial which employed staff for up to 6 months to support one wave of delivery. This means that staffing and overhead costs would be divided across delivery to a larger number of families. Training would be a fixed cost, delivered once at the beginning of the year, and the remaining weeks of the year would be dedicated to participant recruitment and community liaison between rounds. Physical goods can be shared across waves (with an assumed replacement rate of $15 \%$ ). Other material costs are mostly composed of transport and food for participants, so costs increase proportional to the number of families receiving the programme.

In order to account for uncertainty in scaling assumptions, we also present our costing results assuming a more conservative estimate of costs at scale (total modelled costs plus 50\%). Finally, after consultation with the implementing NGO, we also estimated costs using a 'lean model' of programme delivery. In this scenario, three costly components of implementation that encourage attendance (transport, a full meal for all participants and home visits to update families that are unable to attend a session) are omitted from the delivery model, based on our finding that participation and implementation characteristics were not key determinants of programme effectiveness. ${ }^{33}$ Full descriptions of the assumptions made when modelling costs at scale are included in online supplementary table 1 .

All costs were incurred in South African Rand and were converted to US dollars using the OECD average annual exchange rate for the year of programme implementation, 2015. ${ }^{34}$ All costs presented, including models of costs at scale, therefore reflect 2015 prices.

\section{Programme outcomes}

The primary outcome of the trial, reduction in incidence of reported abuse in the past month, was used as the measure of cost-effectiveness of the programme. The full results of the trial, including all analysis relating to secondary outcomes, has been published elsewhere. ${ }^{29}$ Only physical and emotional abuse were considered for the cost-effectiveness analysis, as the main trial was not appropriately powered to detect changes in the incidence of sexual abuse and neglect due to low report levels at baseline.

Abusive parenting was measured using an adapted version of the International Society for Prevention of Child Abuse and Neglect Child Abuse Screening Tool (ICAST),${ }^{35}$ the ICAST-Trial, completed by both caregiver and the teen. To estimate the effect that the trial had on the number of abusive incidents reported for the past month, thresholds of abuse on the ICAST scale were identified, in line with the definitions used in the UBS OPTIMUS study (which estimated national prevalence levels of abuse in South Africa ${ }^{11}$ ). For physical abuse, any reported incident was defined as abuse. However, for emotional abuse, the two scales differ in their classification. The Juvenile Victimization Questionnaire used by OPTIMUS classifies emotional abuse as any incident in which the child was insulted, called names or told they are not wanted which made the child scared or feel really bad. In contrast, ICAST asks about different types of 
emotional abuse, without linking this to the causation of harm (making the child feel bad), meaning that a single incident of a parent shouting at their child would score a 1 on this subscale. We judged that the two scales are therefore not equivalent and so set a minimum threshold of 3 on the ICAST scale to try and increase sensitivity to true emotional abuse. Alternative thresholds were also tested to check for robustness. In contrast to the full trial results, a composite score of the child and parent report of abuse was used in order to give a single point estimate, similar to measurement conventions in research on child delinquency. ${ }^{36}$

Analysis of the effectiveness outcomes was conducted in Stata V.14.0. To estimate changes in incidence of past month abuse associated with treatment, a linear probability model using ANCOVA specification was generated, with standard errors clustered at the village level.

\section{Programme cost-effectiveness}

To estimate the cost-effectiveness, the difference in probability of past-month abuse was converted to an absolute number of incidents of abuse averted for the number of beneficiaries in the treatment group. Dividing the total cost of the programme by this incident rate gives an estimate of the cost per incident of physical or emotional abuse avoided. Based on (1) the best estimates of disability-adjusted life years (DALYs) lost in South Africa due to different forms of child abuse and (2) the best estimate of abuse incidence in South Africa, we were able to transform our primary outcome (incidents of abuse averted) into DALYs averted. A summary of this transformation, which follows a similar approach to Jan $e t a l^{37}$ is presented in table 1. This allows us to transform our cost-effectiveness ratio into an estimate of cost per DALY averted.

For both estimates of cost-effectiveness, sensitivity analysis was conducted to give a lower and upper bound around the point estimate of cost-effectiveness. This analysis accounted for uncertainty around the effect size by using the $95 \%$ CIs and for uncertainty around the costs of programme delivery at scale. Our approach follows the example of Greco et al which allowed for $50 \%$ uncertainty around the estimated costs of their programme for the prevention of violence in schools. ${ }^{38}$ For cost per DALY gained, we also accounted for uncertainty in the transformation by conducting sensitivity analysis varying the estimate of past-year incidence by $\pm 5 \%$ and the estimate of DALYs per case of abuse averted by $\pm 20 \%$.
In the absence of an existing comprehensive framework, to estimate the potential benefits of the programme we first formulated a framework of the possible economic savings associated with the reduction of childhood violence from the societal perspective based on extensive review of the literature. This framework was adapted from approaches previously used to estimate total economic costs of child maltreatment ${ }^{7}$ and cost-benefit analysis of similar parenting programmes in HICs. ${ }^{2526}$ We identified three types of direct saving (health service use, social service use and court case costs) and five types of indirect saving (the economic value of DALYs averted, longterm health service use averted, productivity loss averted, costs of delinquency to the criminal system averted, and intergenerational costs averted) that could be attributed to the prevention of abuse. Next, we attempted to determine costs attributable to a single case of physical or emotional abuse in each of these categories.

Due to the limitations of data available for the South African context, we were only able to estimate costs associated with productivity loss, social service use and approximate monetary value of DALYs lost. We were able to estimate the cost of social worker time dedicated to the investigation of child maltreatment using the norms set in Barberton's costing of the Social Care Act, scaled to 2015 wages. ${ }^{39}$ Fang et al ${ }^{12}$ provide population estimates for the productivity loss and economic value of DALYs lost due to child maltreatment in South Africa. The monetary value associated with DALY losses is estimated by assuming that one DALY is equivalent to the country's GDP per capita (an approach also used by Brown ${ }^{40}$ to estimate the global economic value of violence). Here, these values were then scaled using the prevalence estimates from Burton et al ${ }^{11}$ to give an approximate average value associated with a case of physical or emotional abuse. The framework and cost calculations for each category are presented in the results section. As these benefits were not measured directly during the trial, the framework and calculated savings remain theoretical.

\section{Patient and public involvement}

There was no patient or public involvement in the development or execution of this research study.

\section{RESULTS}

\section{Cost of implementation during the trial}

During the trial, implementation of the 'Sinovuyo Teen' programme for 270 families across 20 villages cost a total

Table 1 Summary of assumptions and sources used to convert incidents of abuse into disability-adjusted life years (DALYs)

\begin{tabular}{lcc}
\hline Transforming incidents of abuse averted to DALYs averted & Physical abuse (n/\%) & Emotional abuse (n/\%) \\
\hline 1. Absolute DALYs lost due to abuse in South Africa in $2015^{12}$ & 1420744 & 786560 \\
2. Population of children under 18 & 18526600 & $12.1 \%$ \\
3. Incidence of past-year abuse ${ }^{46}$ & $18.6 \%$ & 2241719 \\
4. No of incidents of abuse (calculation: $2 \times 3$ ) & 3445948 & 0.351 \\
\hline 5. DALYs lost/incident abuse (calculation: 1/4) & 0.412 & \\
\hline
\end{tabular}


Table 2 Costs of programme implementation estimated retrospectively for the trial (delivery in one round, to 270 families) and modelled at scale (delivery in three rounds, over 1 year, to up to 1000 families)

\begin{tabular}{|c|c|c|c|c|c|}
\hline & \multicolumn{2}{|c|}{ Costs during trial } & \multicolumn{3}{|c|}{ Modelled costs at scale } \\
\hline & Cost (US\$) & $\%$ & Cost (US\$) & $\%$ & Key scaling assumptions \\
\hline \multicolumn{6}{|l|}{ Set-up } \\
\hline Preparation & 6511 & $5 \%$ & 25135 & $9 \%$ & $\begin{array}{l}\text { Recruitment and community liaison occurs ahead of each } \\
\text { round of implementation (includes preparation staff costs) }\end{array}$ \\
\hline Training & 7153 & $5 \%$ & 7153 & $3 \%$ & $\begin{array}{l}\text { Training costs are fixed; one } 2 \text {-week training for a year of } \\
\text { implementation (includes training staff costs) }\end{array}$ \\
\hline \multicolumn{6}{|c|}{ Programme delivery } \\
\hline Staff costs & 79108 & $58 \%$ & 112645 & $43 \%$ & $\begin{array}{l}\text { Staff costs for } 42 \text { weeks covers three rounds of } 14 \text { weeks, } \\
\text { whereas staff were employed for up to } 36 \text { weeks for one } \\
\text { round during the trial }\end{array}$ \\
\hline $\begin{array}{l}\text { Material } \\
\text { costs }^{*}\end{array}$ & 33483 & $25 \%$ & 106567 & $40 \%$ & $\begin{array}{l}\text { Material costs scaled for three rounds of implementation; } \\
\text { transport and food costs increase proportional to the } \\
\text { number of families }\end{array}$ \\
\hline \multicolumn{6}{|l|}{ Overheads } \\
\hline Overheads $^{\dagger}$ & 9700 & $7 \%$ & 14880 & $6 \%$ & $\begin{array}{l}\text { Decreased level of management support, otherwise } \\
\text { overheads normalised to a full year }\end{array}$ \\
\hline Total & 135954 & & 266380 & & \\
\hline $\begin{array}{l}\text { Cost per } \\
\text { family }\end{array}$ & 504 & & 266 & & \\
\hline
\end{tabular}

*Material costs include transport for facilitators and participants, food for participants, venue hire and required materials. Physical materials for this programme were minimal, but are assumed to have a replacement rate of $15 \%$ over the course of the year.

†Overheads include management support from the main NGO office, and local office running costs, including rent, limited supplies and communication costs (ie, internet, airtime).

of US $\$ 135954$, or US\$504 per family. Staff time during implementation accounted for the majority of the costs (US\$79 108, 58\%). Initial facilitator training accounted for $5 \%$ of the total costs, which includes all of the staff and material costs for the 2 weeks of training required. Preparation, which included community and household visits ahead of implementation, accounted for a further $5 \%$ of the total costs. Material costs during the implementation accounted for $25 \%$ of the total costs. This breaks down into the cost of transporting staff and family to implementation locations (US\$20 056, 15\%), providing food for attendees at each session (US\$11 779, 9\%), and the minimal physical resources required for implementation (printed handouts, flipcharts and a few props; US $\$ 1646$, $1 \%)$. Implementation of home visits to participants who missed sessions required both transport and staff time, accounting for a considerable proportion of the overall programme costs (\$29 978, 22\%).

\section{Programme implementation at scale}

Costs during trial implementation are expected to differ substantially from the delivery costs at scale. As shown in table 2, we estimate that, using the same implementation strategy, the programme could be delivered to up to 1000 families for US\$266 380, or US\$266 per family.

Savings would be achieved by implementing several rounds of the programme sequentially over the course of the year. Training costs, overhead costs and staff time would be divided across delivery to a greater number of families. While physical materials can be shared between groups throughout the year (therefore representing a once-off investment with an assumed replacement rate of $15 \%$ ), within the current delivery model transport and food costs vary according to the number of families enrolled.

A more conservative estimate of costs at scale (total modelled cost plus 50\%) suggests a cost of US $\$ 399$ per family, while an estimate of a scenario using lean programme delivery would cost US $\$ 146$ per family. We expect true programme costs at scale to fall within this range.

\section{Programme effectiveness}

Across the 270 families that received the programme, the treatment group experienced a $10 \%$ reduction in risk of past-month physical abuse ( $95 \%$ CI $2 \%$ to $18 \%, \mathrm{p}=0.01$ ) and $17 \%$ reduction in risk of past-month emotional abuse ( $95 \%$ CI $9 \%$ to $26 \%, \mathrm{p}<0.01$ ), as measured by improvements in specified ICAST subscales. (We conducted sensitivity analysis of this result to alternate thresholds of emotional abuse. Reducing the threshold for emotional abuse to a score of 2 on the ICAST subscale reduced the effect size to a $13 \%$ reduction in risk of past-month emotional abuse $(95 \%$ CI $4 \%$ to $22 \%, \mathrm{p}<0.01)$. Increasing the threshold for emotional abuse to a score of 4 reduced the effect size to a $8 \%$ risk reduction $(95 \%$ CI $-17 \%$ to $1 \%, \mathrm{p}=0.092)$. We continued with our analysis using a threshold of 3 on the ICAST subscale as this best matches 
Table 3 Estimated cost per incident of physical or emotional abuse averted, including sensitivity analysis to uncertainty around the effect size and the costs of implementation at scale

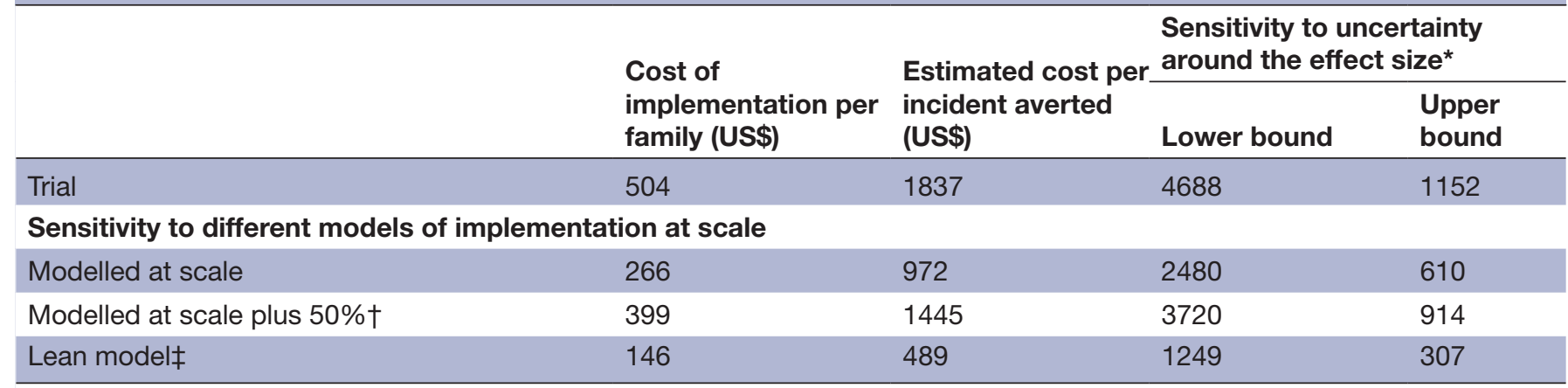

${ }^{*}$ Bounds are calculated using the lower and upper values of the $95 \% \mathrm{Cl}$ around the effect size.

†This model adds $50 \%$ of the calculated budget for the delivery of the programme at scale, allowing for unforeseen variations in context that may increase costs.

¥This model assumes delivery at scale with the modelled cost, but with reduced transportation, and no food or home visits for participants.

the OPTIMUS definition of emotional abuse.) This level of risk reduction equates to 27 incidents of past-month physical abuse, and 47 incidents of past-month emotional abuse, avoided as a result of the programme (95\% CI 29 to 118 incidents total), in comparison with families in the control group, who received the comparator handwashing programme.

\section{Cost-effectiveness}

The cost per incident of past-month abuse avoided during the trial was US $\$ 1862$ (95\% CI US $\$ 4688$ to US $\$ 1152$ ). Assuming continued results at scale, the cost per incident of abuse avoided decreases to US $\$ 972$ (95\% CI US $\$ 2480$ to $\$ 610)$.

Table 3 presents the full cost-effectiveness analysis results, including sensitivity analysis. There is a large range in the cost per incident averted, from US\$307/incident of abuse averted, assuming the upper bound of the effect size, and the leanest delivery model, to US\$4688/ incident of abuse averted taking the lower bound of the effect size and the costs of implementation at trial.

Using the transformation described in table 1, this equates to a cost per DALY averted of US $\$ 4952$ during the trial (US\$3157-12 485 on sensitivity analysis) and US\$2645 at scale (US\$1296-9938 on sensitivity analysis), as presented in online supplementary file 1 .

\section{Estimating costs saved through programme benefits}

Our suggested framework to summarise the potential economic benefits associated with averting abuse in South Africa is presented in table 4. Given the population-level economic value of violence for South Africa presented by Fang $e t a l^{2}$ and prevalence rates presented by Burton $e t$ $a l,{ }^{11}$ we calculated that the value of lost DALYs for each case of childhood physical and emotional abuse averted is US\$1682 and US\$1979, respectively. Similarly, data from Fang et al were used to calculate the average loss in productivity attributable to each case (US\$408 and US\$322). We were also able to calculate the cost of social worker time to investigate a single case given the expected norms presented by Barberton ${ }^{39}$ as US $\$ 533$. However, we were unable to identify reliable data sources for any other components of the framework. This gives us a conservative estimate of saving per case averted of US\$2644 for physical abuse and US\$2804 for emotional abuse. As we were unable to source data to estimate costs saved across the other categories in our framework, and have not considered any of the secondary outcomes of Sinovuyo Teen, full cost-benefit analysis of the programme is not possible at this stage. As a result, our estimates of costs averted is conservative and likely to underestimate the true value of benefits generated by the programme.

\section{DISCUSSION}

This is the first study to fully explore the cost of implementing a parenting programme in a LMIC. The running cost of US $\$ 504$ per family is a fraction of the cost of similar programmes in HICs ${ }^{4142}$ and is lower but comparable with the cost of similar parenting programmes in Thailand and Liberia (US\$650-900 per family). Implementation of the programme for 270 families resulted in an estimated 73 incidents of physical or emotional abuse being averted, at a cost of incident averted of US\$1862, or cost per DALY averted of US\$4952.

While there are few available comparisons for the cost-effectiveness of this study, this programme was implemented at slightly lower cost per DALY than a similar South African programme to prevent intimate partner violence (US $\$ 9646$ per DALY during trial implementation, in 2015 US dollars) ${ }^{37}$ Additionally, the programme performs favourably against the WHO general cost-effectiveness threshold, which suggests a cost-effective programme should achieve a cost of intervention per DALY averted of less than three times the country's annual GDP per capita (2015 GDP per capita for South Africa was US\$5746).

Modelling the costs at scale demonstrate that it may be possible to deliver the programme for as little as US\$146 per family. Assuming effectiveness at scale is 
Table 4 Framework for estimating the benefits associated with averting a case of childhood physical or emotional abuse, from a societal perspective

\begin{tabular}{|c|c|c|c|c|}
\hline \multirow[b]{2}{*}{ Category of benefit } & \multirow[b]{2}{*}{ Rationale } & \multirow[b]{2}{*}{ Data source } & \multicolumn{2}{|c|}{$\begin{array}{l}\text { Saving per case of } \\
\text { abuse averted* (US\$) }\end{array}$} \\
\hline & & & Physical & Emotional \\
\hline \multicolumn{5}{|l|}{ Direct saving } \\
\hline Health service use & $\begin{array}{l}\text { Costs associated with } \\
\text { immediate injuries }\end{array}$ & $\begin{array}{l}\text { Amount attributable to abuse } \\
\text { unknown for SA }\end{array}$ & - & - \\
\hline Social service use & $\begin{array}{l}\text { Costs associated with } \\
\text { investigation and immediate } \\
\text { response to an abuse case }\end{array}$ & $\begin{array}{l}\text { Social worker time approximated } \\
\text { from current wages and norms set } \\
\text { by Barberton's costing of SA social } \\
\text { care bill, assumes all cases are } \\
\text { investigated appropriately }\end{array}$ & 553† & \\
\hline Child care and court costs & $\begin{array}{l}\text { Costs associated with } \\
\text { processing and supporting } \\
\text { a child in foster care, the } \\
\text { outcome of most severe } \\
\text { abuse cases in SA }\end{array}$ & $\begin{array}{l}\text { Total child welfare bill was ZAR } \\
1.58 \text { billion in } 2015 \text {, but proportion } \\
\text { attributable to physical or } \\
\text { emotional abuse unknown }\end{array}$ & - & - \\
\hline
\end{tabular}

Indirect saving

DALYs averted
Lifetime costs associated with attributable increased risk of mental health problems, substance abuse and STIs

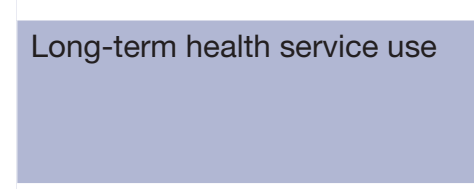

Productivity loss
Costs associated with use of health service associated with mental health problems, substance abuse and STIs

\section{substance abuse and STIs}

Fang et $a^{12}$ (which assumes that
the monetary value of one DALY is equivalent to a country's GDP per capita), approximated to case level using prevalence from Burton et $\mathrm{al}^{11}$
Amount attributable to abuse unknown for SA

Estimated value of individual

Estimated value of individual
productivity loss for a victim

Fang et al,,$^{12}$ approximated to case 408

$-$
abuse due to long-term health et $\mathrm{al}^{11}$ impacts

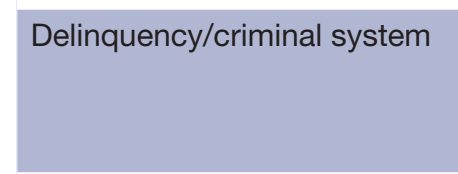

Intergenerational costs
Victims of childhood abuse are more likely to become criminals incurring costs to the criminal system

Victims of childhood abuse are more likely to become the perpetrators of abuse, incurring costs through several generations.

\footnotetext{
Total saving per case averted

*All costs presented in 2015, nominal US dollars, to allow direct comparison with the costs of programme implementation.

†As this is a strong assumption for the SA context, we conducted sensitivity analysis of total savings, making an alternative assumption that only $20 \%$ of cases are fully investigated. This results in a reduction in the total saving per case averted to US $\$ 2201$ and US $\$ 2361$ for physical and emotional abuse, respectively. However, the programme maintains a net benefit both at trial and at scale.

DALY, disability-adjusted life year; HIC, high-income country; SA, South Africa; STI, sexually transmitted infection.
}

Unknown for SA, but form a considerable proportion of the savings attributable to parenting programmes in $\mathrm{HICs}^{26}$

Proportion of victims that become perpetrators unknown for $\mathrm{SA}^{6}$ maintained, this could drastically reduce the cost per incident averted. For comparison, the potential savings associated with averting abuse are large. A conservative estimate, given the constraints of available data, suggests that societal savings of approximately US\$2700 are made for each case averted. Therefore, while full cost-benefit analysis was not within the scope of this work, these results provide a proof of principle that implementation of a parenting programme to prevent abuse is likely to become cost-saving over the life course of the individuals enrolled.

It is not yet clear whether these costs are acceptable to policy-makers within LMICs, although the programme is currently being scaled up to reach around 400000 families in South Africa, Uganda, Tanzania, Lesotho, Democratic Republic of Congo, Haiti, South Sudan, Kenya, Zimbabwe, Cote d'Ivoire, Swaziland, Philippines and planned in Cameroon, Nigeria and North India. 
Further research is required to estimate costs when the programme is implemented by different agencies in these different contexts. For example, costs such as local facilitator salaries are likely to be lower in some of these countries than in South Africa, but additional security costs will arise in conflict settings. Additionally, some implementing agencies have not provided transport, food and home visits for participants suggesting the lean model of delivery costs at scale is achievable. Further research will be needed to establish how these implementation changes may affect attendance, acceptability and effectiveness of the programme, particularly for highly disadvantaged families. ${ }^{33}$ Future research will also need to investigate whether programme impact can be sustained over the long term, beyond the period of 5-9 months covered in the trial.

It should be highlighted that, in addition to a reduction in abuse, trial results showed that the programme was also associated with improvements across a number of secondary outcomes, including a substantial drop in caregiver depression and both caregiver and adolescent substance abuse. ${ }^{33}$ Estimating the cost-effectiveness of benefits of the programme in relation to these outcomes was beyond the scope of this work. However, as each of these outcomes also represent substantial costs to society, ${ }^{43} 44$ it is possible that we are presenting an underestimate of the true cost-effectiveness of the programme.

Similarly, we have made no attempt here to estimate any spillover effects of the programme. While only one caregiver and one teen attended the programme (and were interviewed), there are multiple children in the majority of families (adolescents share the house with an average of 2.7 other under 18-year-olds). If the caregiver has reduced abusive practices with one child, it is likely they will also change their behaviour with any other children in the household, meaning more incidents of abuse may have been avoided than we have recorded. Qualitative evidence in the pilot stage in fact indicated that there was spillover of the programme throughout members of the community. ${ }^{31}$ Again, this suggests that we are likely underestimating the true cost-effectiveness of the programme.

It is not possible to say whether these results from the rural Eastern Cape of South Africa, from a population where the burden of maltreatment is particularly high, will translate into other settings. Full prospective cost-benefit analysis, including all outcomes, could be conducted alongside scale-up of the programme to capture actual costs at scale and to estimate if and when the programme becomes truly cost saving.

\section{CONCLUSION}

The global costs of child abuse and its consequences are high. There is evidence that the prevalence of child abuse may be highest in LMICs, ${ }^{9}$ yet the vast majority of research into the prevention of child maltreatment takes place in HICs. There have been several international calls to action to correct this imbalance. Parenting programmes are one method to effectively prevent abuse, yet little is known about their costs and their effectiveness in low-resource settings. This analysis demonstrates that a programme may be run at relatively low cost in the rural Eastern Cape, South Africa and can effectively reduce the incidence of abuse. Crucially, it demonstrates the potential for these costs to be offset by savings accrued through the prevention of abuse. Despite the limitations of this analysis, it is an important first insight into the potential economic impact of effectively preventing abuse in this context.

Acknowledgements We thank all the adolescents, parents and their communities who participated in this study. We are extremely grateful for the work of our implementing partners, Clowns Without Borders South Africa, and in particular Jamie Lachman, for supporting the acquisition ofrequired costing data.

Contributors AR, LDC, MC and JIS contributed towards conceptualising and designing this study. AR conducted data acquisition, cleaning and analysis. All authors provided comments towards drafts of the article and approved the final version for publication.

Funding AR was funded to complete this study by the Oxford University Clinical Academic Graduate School Research Elective Bursary. The intervention and randomised controlled trial were supported by the European Research Council (ERC) under the European Union's Seventh Framework Programme (FP7/20072013) with ERC grant agreement 313421, Unicef Innocenti Office of Research, Unicef South Africa, the John Fell Fund, the Leverhulme Trust (PLP-2014-095), the Cambridge Trust and the University of Oxford's ESRC Impact Acceleration Account (1311-KEA-004 and 1602-KEA-189). The South African National Department of Social Development provided in-kind support through posting social workers to be trained as programme facilitators. Ongoing scale-up of the programme is being supported by USAID, PEPFAR, Unicef South Africa and World Childhood Foundation. LDC, MC and JIS had full access to all the data in the study. AR had final responsibility for the decision to submit for publication.

Disclaimer The funders of this study had no role in study design, data collection, data analysis or writing of the report.

Competing interests LDC and JIS were involved in developing the Sinovuyo Caring FamiliesProgramme for Parents and Teens, which is licensed under a Creative Commons 4.0 Noncommercial No Derivatives license.

Patient consent for publication Not required.

Ethics approval Ethical approval for the trial was obtained from the Institutional Review Boardsof the University of Oxford (SSD/CUREC2/11-40) and University of Cape Town (PSY2013-46) and by the Provincial Government Departments of Social Development and Education.

Provenance and peer review Not commissioned; externally peer reviewed.

Data availability statement № additional data are available

Open access This is an open access article distributed in accordance with the Creative Commons Attribution Non Commercial (CC BY-NC 4.0) license, which permits others to distribute, remix, adapt, build upon this work non-commercially, and license their derivative works on different terms, provided the original work is properly cited, appropriate credit is given, any changes made indicated, and the use is non-commercial. See: http://creativecommons.org/licenses/by-nc/4.0/.

\section{REFERENCES}

1. Hillis S, Mercy J, Amobi A, et al. Global prevalence of past-year violence against children: a systematic review and minimum estimates. Pediatrics 2016;137

2. Cluver L, Orkin M, Boyes ME, et al. Child and adolescent suicide attempts, suicidal behavior, and adverse childhood experiences in South Africa: a prospective study. J Adolesc Health 2015;57:52-9.

3. Hughes K, Bellis MA, Hardcastle KA, et al. The effect of multiple adverse childhood experiences on health: a systematic review and meta-analysis. Lancet Public Health 2017;2:e356-66.

4. Norman RE, Byambaa M, De R, et al. The long-term health consequences of child physical abuse, emotional abuse, and 
neglect: a systematic review and meta-analysis. PLoS Med 2012;9:e1001349.

5. Widom CS. Does violence beget violence? A critical examination of the literature. Psychol Bull 1989;106:3-28.

6. Thornberry TP, Henry KL. Intergenerational continuity in maltreatment. J Abnorm Child Psychol 2013;41:555-69.

7. Pereznieto $\mathrm{P}$, Montes $\mathrm{A}$, Routier $\mathrm{S}$, et al. The costs and economic impact of violence against children, 2014. Available: https://www. childfund.org/uploadedFiles/public_site/media/ODI Report The cost and economic impact of violence against children.pdf

8. Ward C, Sanders MR, Gardner F, et al. Preventing child maltreatment in low- and middle-income countries: parent support programs have the potential to buffer the effects of poverty. Child Abuse \& Neglect 2016;54:7-107.

9. Runyan DK, Eckenrode J. International perspectives on the epidemiology of child neglect and abuse. Ann Nestle 2004;62:1-12.

10. Mock Cet al. Child injuries and violence: the new challenge for child health. Bull World Health Organ 2008;2008.

11. Burton P, Ward C, Artz L, et al. The Optimus study on child abuse, violence and neglect in South Africa. Cape Town Centre for Justice Crime, 2015.

12. Fang X, Fry DA, Ganz G, et al. The economic burden of violence against children in South Africa. Report to Save the Children South Africa. Georg State Univ Univ Cape T Edinburgh, 2016.

13. Fang X, Brown DS, Florence CS, et al. The economic burden of child maltreatment in the United States and implications for prevention. Child Abuse Negl 2012;36:156-65.

14. Habetha S, Bleich S, Weidenhammer J, et al. A prevalence-based approach to societal costs occurring in consequence of child abuse and neglect. Child Adolesc Psychiatry Ment Health 2012;6.

15. Cost of Domestic Violence to the Australian Economy: Part 1. 2004. https://www.ncjrs.gov/App/Publications/abstract.aspx?ID=234767

16. Butchart A, Harvey AP, Mian M, et al. Preventing child maltreatment: a guide to taking action and generating evidence. World Heal Organ, 2006.

17. Vlahovicova K, Melendez-Torres GJ, Leijten P, et al. Parenting programs for the prevention of child physical abuse recurrence: a systematic review and meta-analysis. Clin Child Fam Psychol Rev 2017:1-15 http://link.springer.com/

18. Knerr W, Gardner F, Cluver L. Improving positive parenting skills and reducing harsh and abusive parenting in low- and middle-income countries: a systematic review. Prev Sci 2013;14:352-63.

19. Mejia A, Calam R, Sanders MR. A review of parenting programs in developing countries: opportunities and challenges for preventing emotional and behavioral difficulties in children. Clin Child Fam Psychol Rev 2012;15:163-75.

20. Puffer ES, Annan J, Sim AL, et al. The impact of a family skills training intervention among Burmese migrant families in Thailand: a randomized controlled trial. PLOS One 2017;12.

21. Sim A, Puffer E, Green E, et al. Parents make the difference findings from a randomized impact evaluation of a parenting program in rural Liberia. Available: http://www.bettercarenetwork. org/sites/default/files/Parents Make the Difference - Impact Evaluation.pdf

22. Mejia A, Calam R, Sanders MR. A pilot randomized controlled trial of a brief parenting intervention in low-resource settings in Panama. Prev Sci 2015;16:707-17.

23. Charles JM, Bywater T, Edwards RT. Parenting interventions: a systematic review of the economic evidence. Child Care Health Dev 2011:37:462-74.

24. Stevens M. The cost-effectiveness of UK parenting programmes for preventing children's behaviour problems - a review of the evidence. Child Fam Soc Work 2014;19:109-18.
25. Mihalopoulos C, Sanders MR, Turner KMT, et al. Does the triple P-Positive parenting program provide value for money? Aust $N Z \mathrm{~J}$ Psychiatry 2007;41:239-46.

26. Bonin E-M, Stevens M, Beecham J, et al. Costs and longer-term savings of parenting programmes for the prevention of persistent conduct disorder: a modelling study. BMC Public Health 2011;11.

27. Prinz RJ, Sanders MR, Shapiro CJ, et al. Population-based prevention of child maltreatment: the U.S. triple $\mathrm{P}$ system population trial. Prev Sci 2009;10:1-12.

28. International Rescue Committee (IRC). Cost effectiveness analysis improving parenting practices in Liberia and Thailand, 2016. Available: https://www.rescue.org/report/cost-effectivenessparental-coaching-programs

29. Cluver LD, Meinck F, Steinert Jl, et al. Parenting for lifelong health: a pragmatic cluster randomised controlled trial of a noncommercialised parenting programme for adolescents and their families in South Africa. BMJ Glob Health 2018;3:e000539.

30. Cluver LD, Lachman JM, Ward CL, et al. Development of a parenting support program to prevent abuse of adolescents in South Africa: findings from a pilot pre-post study. Res Soc Work Pract 2016.

31. Cluver L, Meinck F, Yakubovich A, et al. Reducing child abuse amongst adolescents in low- and middle-income countries: a prepost trial in South Africa. BMC Public Health 2016;16.

32. Cluver L, Meinck F, Shenderovich $Y$, et al. A parenting programme to prevent abuse of adolescents in South Africa: study protocol for a randomised controlled trial. Trials 2016;17.

33. Shenderovich Y, Eisner M, Cluver L, et al. Delivering a parenting programme in South Africa: the impact of implementation on outcomes. J Child Fam Stud.

34. OECD. Exchange rates (indicator), 2018. Available: https://data. oecd.org/conversion/exchange-rates.htm

35. Zolotor AJ, Runyan DK, Dunne MP, et al. ISPCAN child abuse screening tool children's version (ICAST-C): instrument development and multi-national pilot testing. Child Abuse Negl 2009;33:833-41.

36. Achenbach TM, McConaughy SH, Howell CT. Child/adolescent behavioral and emotional problems: implications of cross-informant correlations for situational specificity. Psychol Bull 1987;101:213-32.

37. Jan S, Ferrari G, Watts $\mathrm{CH}$, et al. Economic evaluation of a combined microfinance and gender training intervention for the prevention of intimate partner violence in rural South Africa. Health Policy Plan 2011;26:366-72.

38. Greco G, Knight L, Ssekadde W, et al. Economic evaluation of the good school toolkit: an intervention for reducing violence in primary schools in Uganda. BMJ Glob Health 2018;3.

39. Barberton C. The cost of the children's bill, 2005.

40. Brown DW. Economic value of disability-adjusted life years lost to violence: estimates for WHO Member States. Rev Panam Salud Publica 2008;24:203-9.

41. Edwards RT, Jones C, Berry V, et al. For Authors Incredible Years parenting programme: cost-effectiveness and implementation. $J$ Child Serv J Child Serv Iss J Child Serv 2016;11:54-72.

42. Washington State Institue for Public Policy. Triple P positive parenting program: level 4, individual. Available: http://www.wsipp. wa.gov/ReportFile/1500

43. Global Health Estimates 2016. Disease burden by cause, age, sex, by country and by region, 2000-2016. Geneva: World Heal Organ, 2018.

44. Matzopoulos RG, Truen S, Bowman B, et al. The cost of harmful alcohol use in South Africa. S Afr Med J 2014;104:127-32.

45. Hall K, Sambu W. South African Child Gauge, 2016.

46. Meinck F, Cluver LD, Boyes ME, et al. Physical, emotional and sexual adolescent abuse victimisation in South Africa: prevalence, incidence, perpetrators and locations. J Epidemiol Community Health 2016;70:910-6. 